Supplementary Figure S4. The identified proteins and abundance biases in 18 pathways. These pathway included Complement system (A), Alzheimer's disease (B), PPAR signaling pathway (C), Cell communication (D), Hematopoietic cell lineage (E), Folate biosynthesis (F), Adipocytokine signaling pathway (G), Inositol phosphate metabolism (H), Type II diabetes mellitus (I), Fatty acid metabolism (J), Arginine and praline metabolism (K), ECM-receptor interaction (L), TGF-beta signaling pathway (M), Coagulation cascade (N), Small cell lung cancer $(\mathrm{O})$, Insulin signaling pathway $(\mathrm{P})$, Focal adhesion $(\mathrm{Q})$, Long-term depression $(\mathrm{R})$. The $\mathrm{p}$ value of identified protein was digitized to the length of the bar in each pathway. 
Complement system

Complement component C4B

Complement component 4A

Complement $\mathrm{C} 4$ precursor

C4B1

Complement C3 precursor

C4b-binding protein alpha chain precursor

Splice Isoform 1 of Complement factor B precursor

Complement C1q subcomponent, A chain precursor Complement component $\mathbf{C 8}$ gamma chain precursor

Ficolin 3 protein

Ficolin 2 protein

Complement component C8 alpha chain precursor

Complement-activating component of Ra-reactive factor precursor Splice Isoform 1 of Mannan-binding lectin serine protease 2 precursor

Complement component C7 precursor

Mannose-binding protein $\mathrm{C}$ precursor

Complement factor I precursor

Complement $\mathrm{C} 1 \mathrm{q}$ subcomponent, $\mathrm{C}$ chain precursor

Complement $\mathrm{C} 1 \mathrm{r}$ subcomponent precursor Complement component C8 beta chain precursor

C4b-binding protein beta chain precursor

Complement component C9 precursor

Complement $\mathrm{C} 1 \mathrm{~s}$ subcomponent precursor

Complement C2 precursor

SERPINC1 protein

Complement C5 precursor

Complement component $\mathbf{C 6}$ precursor Adipsin/complement factor D precursor

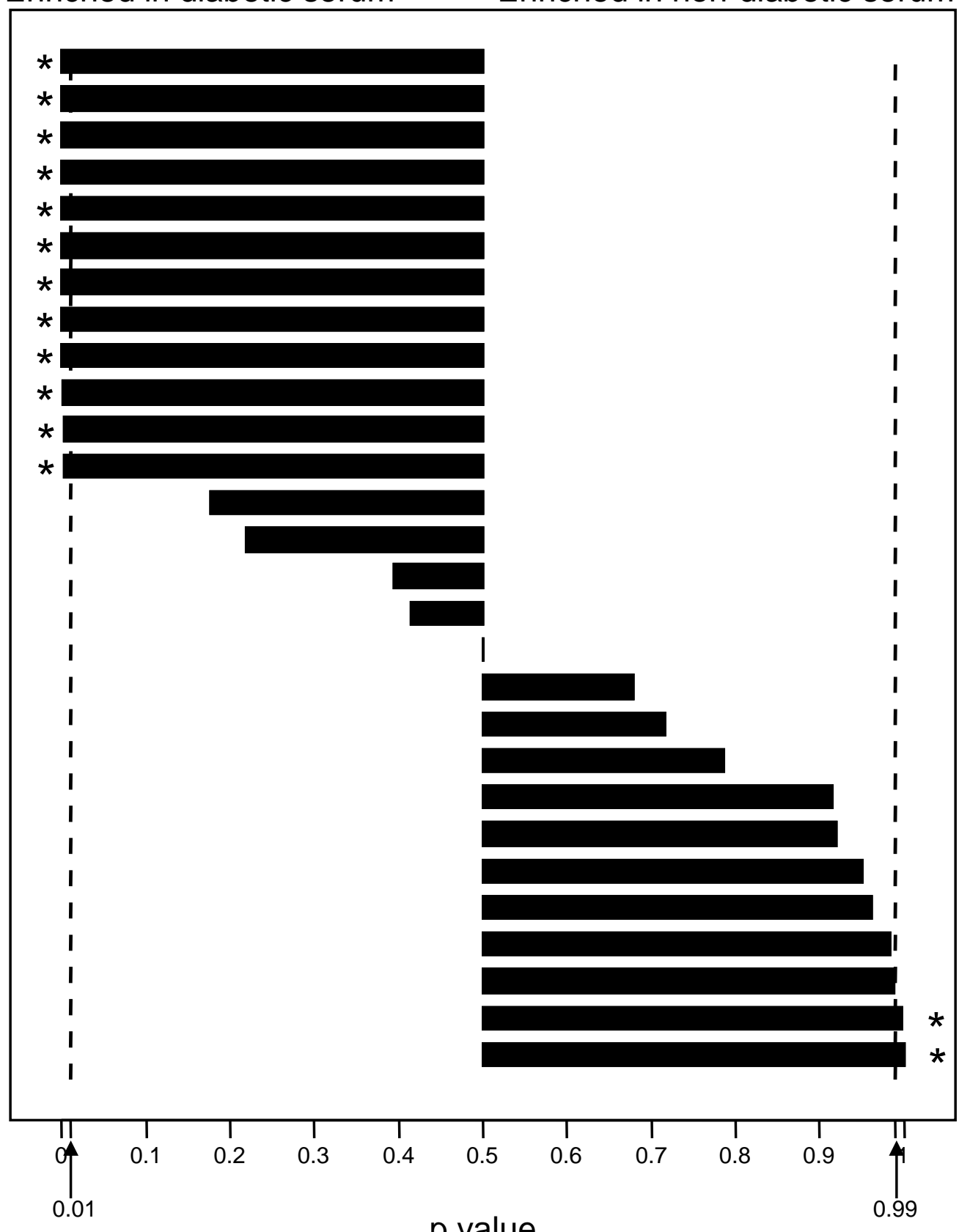




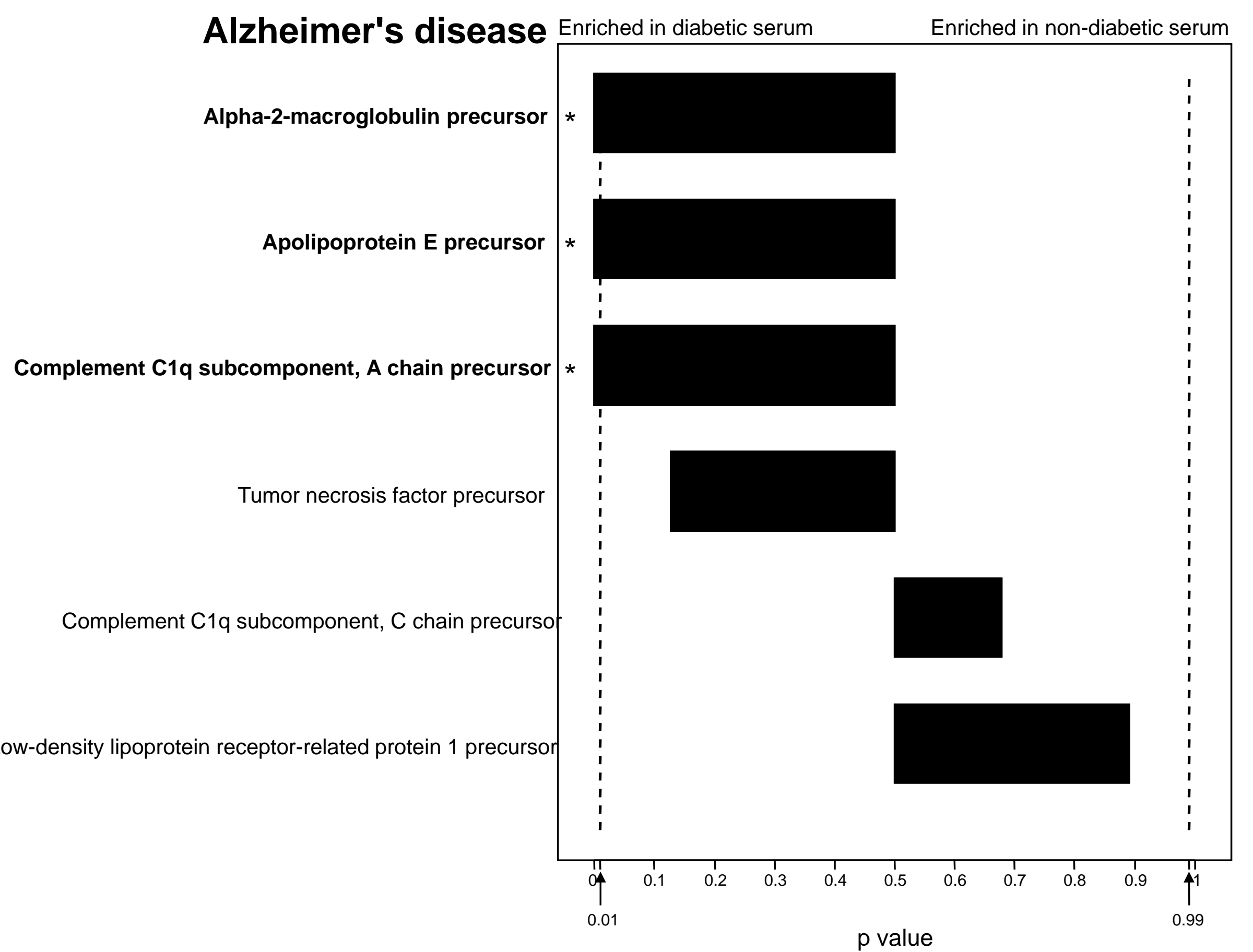


PPAR signaling pathway Enriched in diabetic serum Enriched in non-diabetic serum

Apolipoprotein C-III precursor

Apolipoprotein A-I precursor

Apolipoprotein A-II precursor

Adiponectin precursor

Splice Isoform Long of Long-chain-fatty-acid--CoA ligase 4

Carnitine O-palmitoyltransferase II, mitochondrial precursor

Retinoic acid receptor RXR-gamma

Ubiquitin and ribosomal protein S27a

Splice Isoform 1 of Phospholipid transfer protein precursor

Sorbin and $\mathrm{SH} 3$ domain containing 1

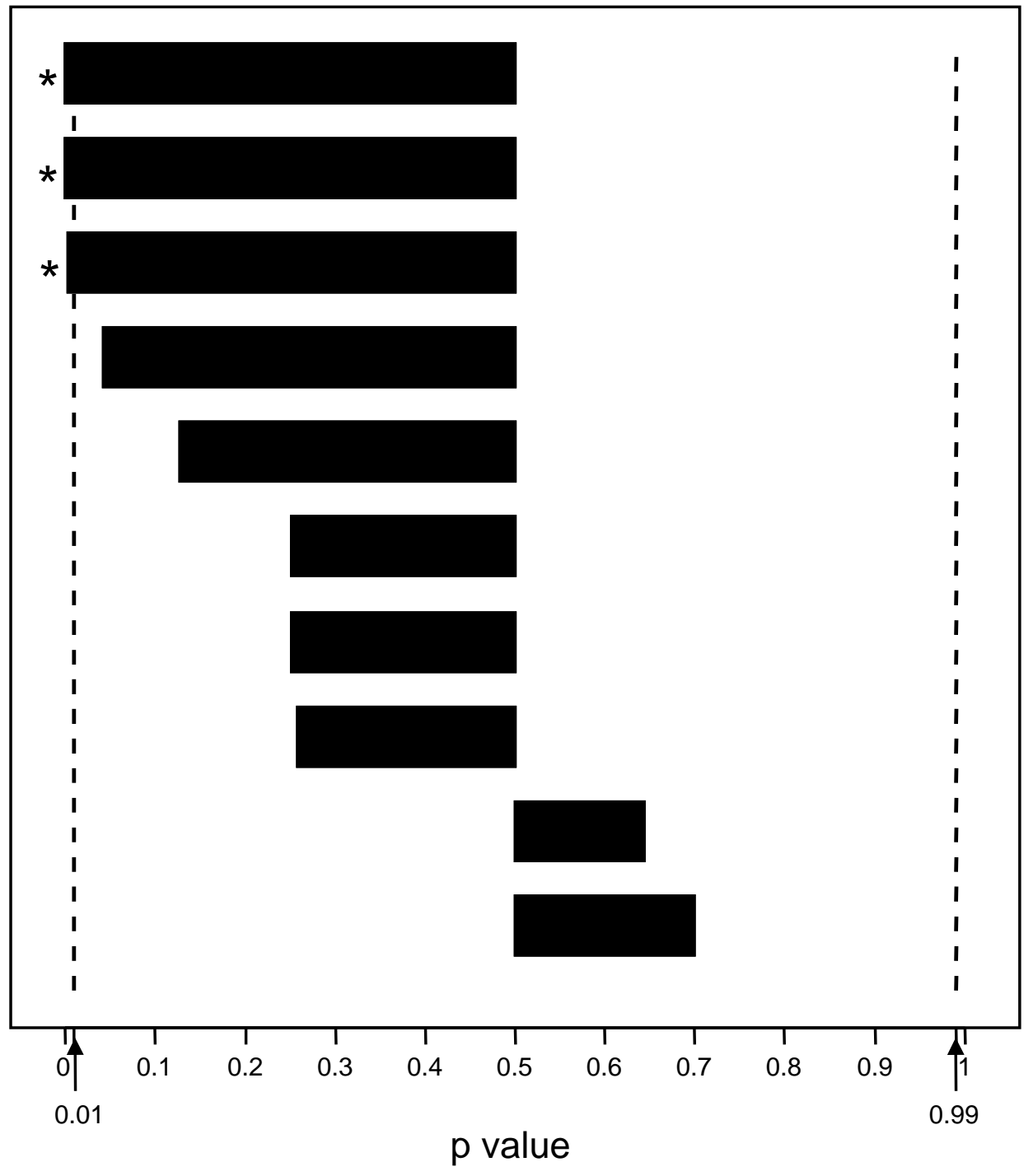


Cell Communication

Keratin, type I cytoskeletal 12 Keratin, type I cytoskeletal 15

Keratin, type I cytoskeletal 16

Keratin, type I cytoskeletal 17

Keratin, type I cytoskeletal 13

Hypothetical protein FLJ20261

Keratin, type I cytoskeletal 14

Keratin, type II cytoskeletal 6A

Keratin, type II cytoskeletal 6B

Keratin, type II cytoskeletal $6 \mathrm{E}$ Keratin, type II cytoskeletal 2 epidermal Keratin $6 L$

Keratin, type I cuticular HA3-II

Keratin, type II cytoskeletal 5

Keratin, type II cuticular HB5

Thrombospondin-4 precursor

Thrombospondin-2 precursor Desmoglein-2 precursor COL3A1 protein

Type I inner root sheath specific keratin 25 irs 3 Collagen alpha $3(\mathrm{~V})$ chain precursor Similar to Lamin A/C

Keratin, type II cytoskeletal 4 Keratin b20

Von Willebrand factor precursor Keratin 9

Keratin, type II cytoskeletal 3 Thrombospondin 1 precursor Keratin 6 irs3

Collagen alpha 1 (III) chain precursor Desmoglein-1 precursor

Splice Isoform A of Collagen alpha 6(IV) chain precurso Laminin, alpha 2 Keratin protein K6irs

Splice Isoform XB of Tenascin-X precursor Vitronectin precursor

Splice Isoform 1 of Tenascin precursor Splice Isoform B of Collagen alpha $1(\mathrm{XI})$ chain precurso Cartilage oligomeric matrix protein precursor

$$
\text { Keratin 1B }
$$

AlphA 1 type II collAgen isoform 2, preproprotein

Splice Isoform 10 of Fibronectin precursor

Splice Isoform 1 of Fibronectin precursor

Fibronectin 1 isoForm 4 preproprotein

Hypothetical protein DKFZp686K08164

$$
\text { Keratin } 10
$$

Actin cytoplasmic 1

Keratin, type I cytoskeletal 10

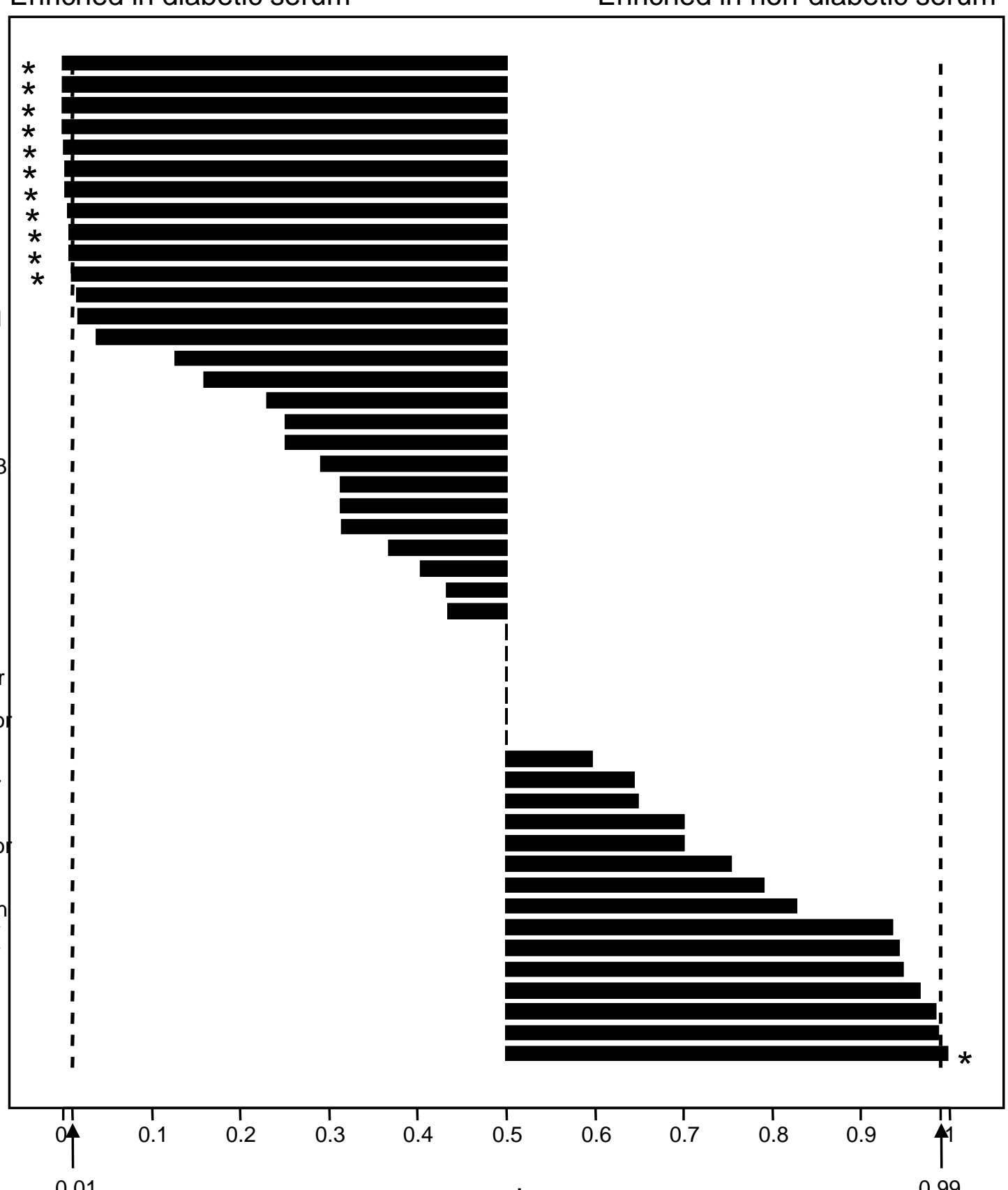

$p$ value 
Monocyte differentiation antigen CD14 precursor

Tumor necrosis factor precursor

Platelet glycoprotein $\mathrm{V}$ precursor

Aminopeptidase $\mathrm{N}$

Platelet glycoprotein Ib alpha chain precursor

Splice Isoform Alpha-3A of Integrin alpha-3 precursor

Soluble interleukin-5 receptor precursor

Transferrin receptor protein 1

Macrophage colony stimulating factor I receptor precursor
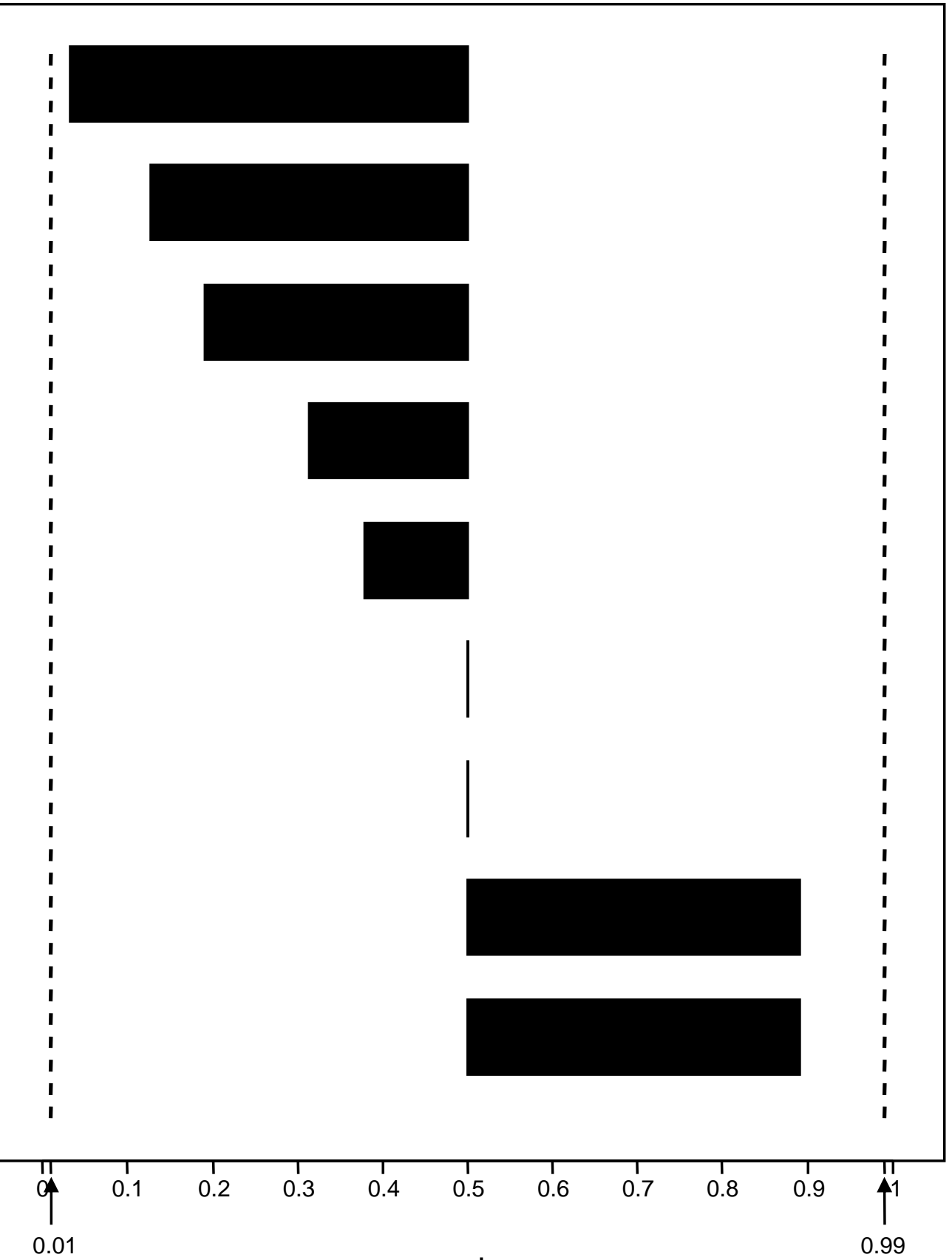

$p$ value 
TFIIH basal transcription factor complex helicase subunit

Splice Isoform 1 of Probable helicase senataxin

Gamma-glutamyl hydrolase precursor

Splice Isoform 1 of Activating signal cointegrator 1 complex subunit 3

Splice Isoform 2 of $\mathrm{E} 1 \mathrm{~A}$ binding protein p400
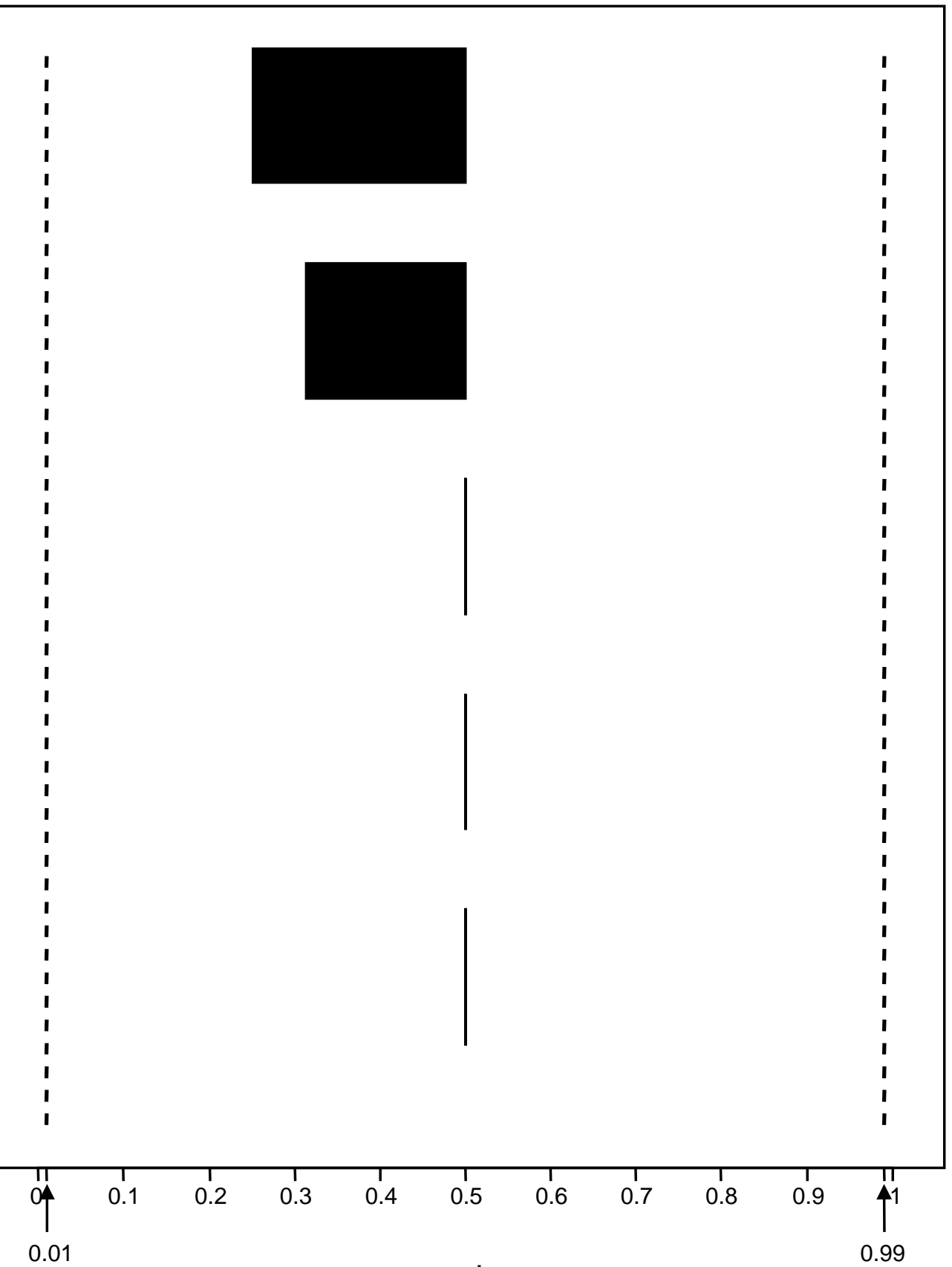

$p$ value 
Splice Isoform Long of Long-chain-fatty-acid--CoA ligase 4

\section{Tumor necrosis factor precursor}

Carnitine O-palmitoyltransferase II, mitochondrial precursor

Retinoic acid receptor RXR-gamma

\section{Splice Isoform 2 of Tyrosine-protein kinase JAK3}

\section{Splice Isoform Alpha-1 of Mitogen-activated protein kinase 10}

Insulin receptor substrate 2 insertion mutant

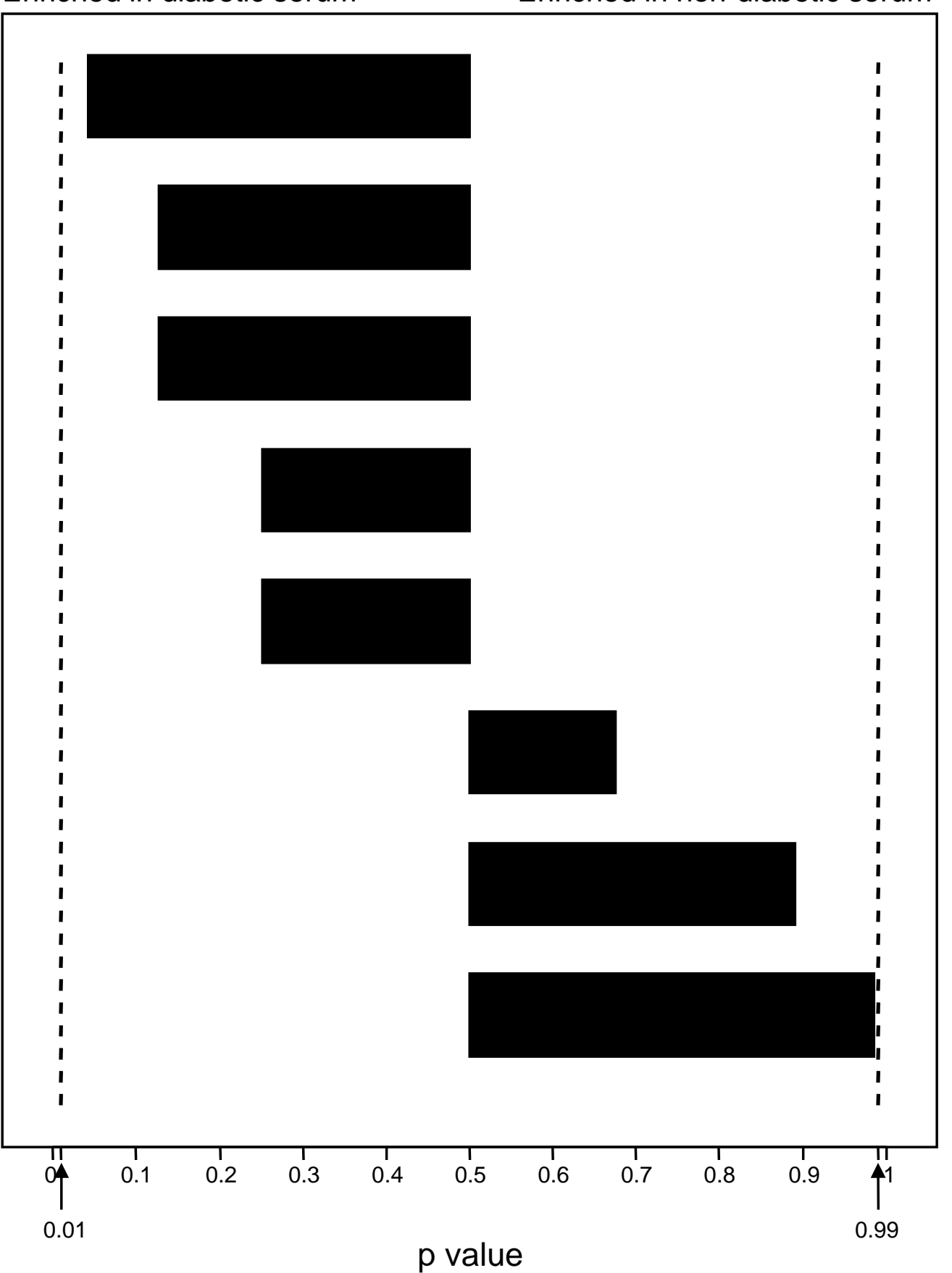


1-phosphatidylinositol-4,5-bisphosphate phosphodiesterase delta 1 Inositol polyphosphate 5-phosphatase

Hypothetical protein PIK3CG

FYVE finger-containing phosphoinositide kinase

1-phosphatidylinositol-4,5-bisphosphate phosphodiesterase beta 2
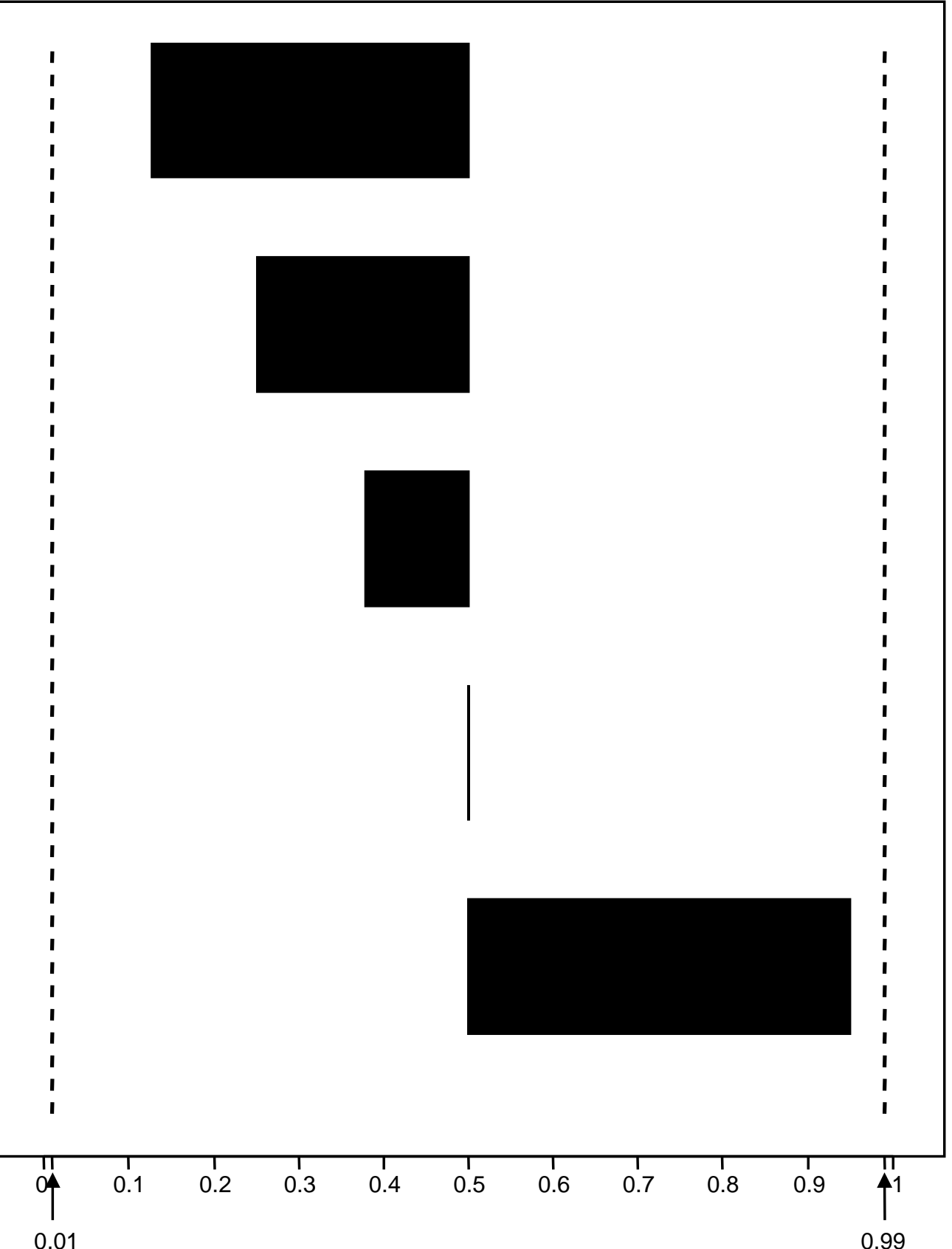

$p$ value 
Splice Isoform Alpha-1 of Mitogen-activated protein kinase 10

Insulin receptor substrate 2 insertion mutant

Tumor necrosis factor precursor

Hypothetical protein PIK3CG

Adiponectin precursor

\author{
Hypothetical protein PIK3CG
}
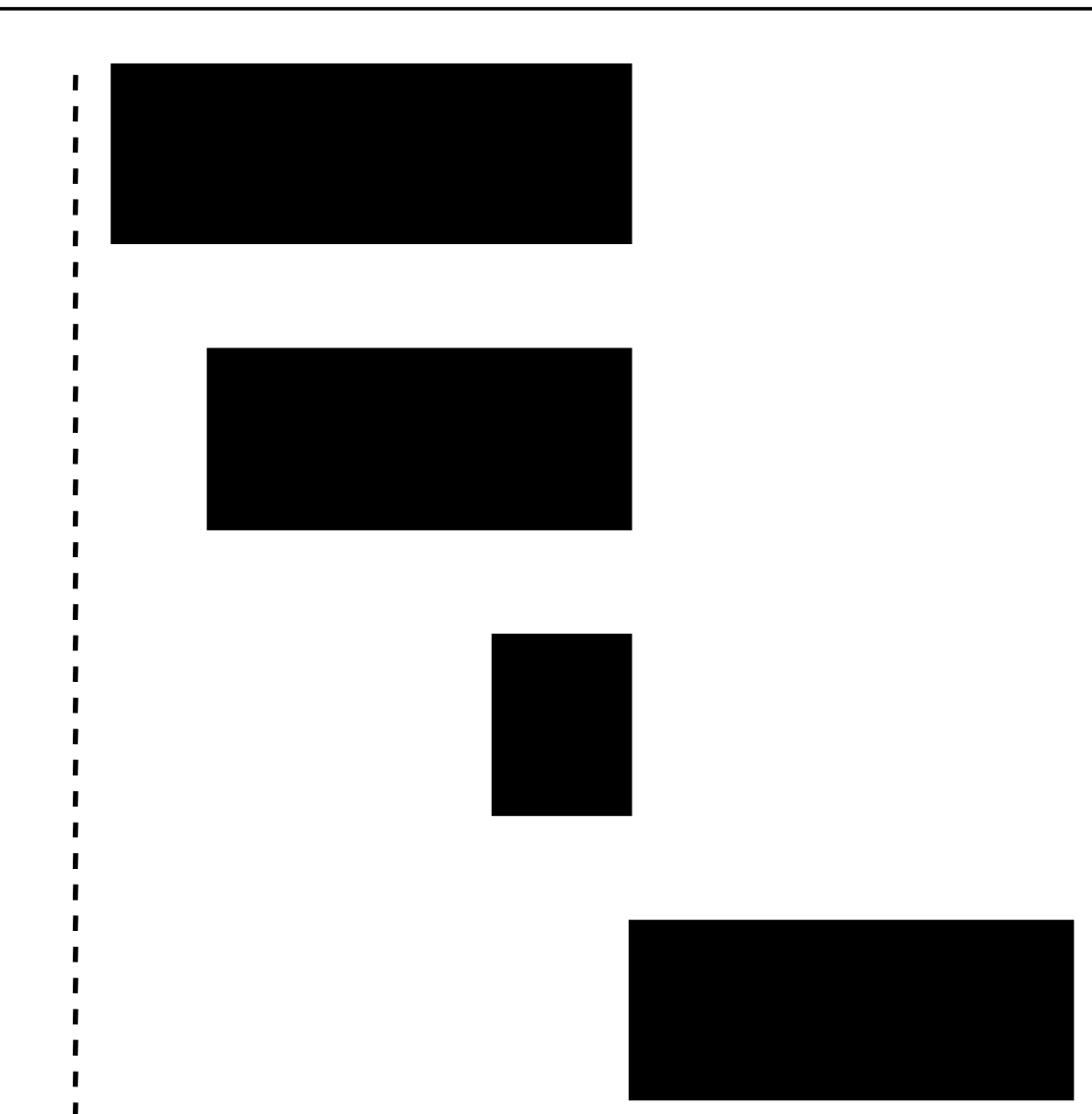


\section{Fatty acid metabolism} Splice Isoform Long of Long-chain-fatty-acid--CoA ligase 4

Carnitine O-palmitoyltransferase II, mitochondrial precursor

Aldehyde dehydrogenase family 7 member A1

Splice Isoform 1 of Acyl-CoA dehydrogenase, very-long-chain specific, mitochondrial precursor

Splice Isoform Long of Glutaryl-CoA dehydrogenase, mitochondrial precursor

Peroxisomal 3,2-trans-enoyl-CoA isomerase
Enriched in diabetic serum

Eniched in diabetic serum

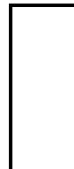

I

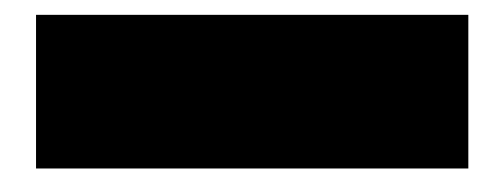

Enriched in non-diabetic serum

He



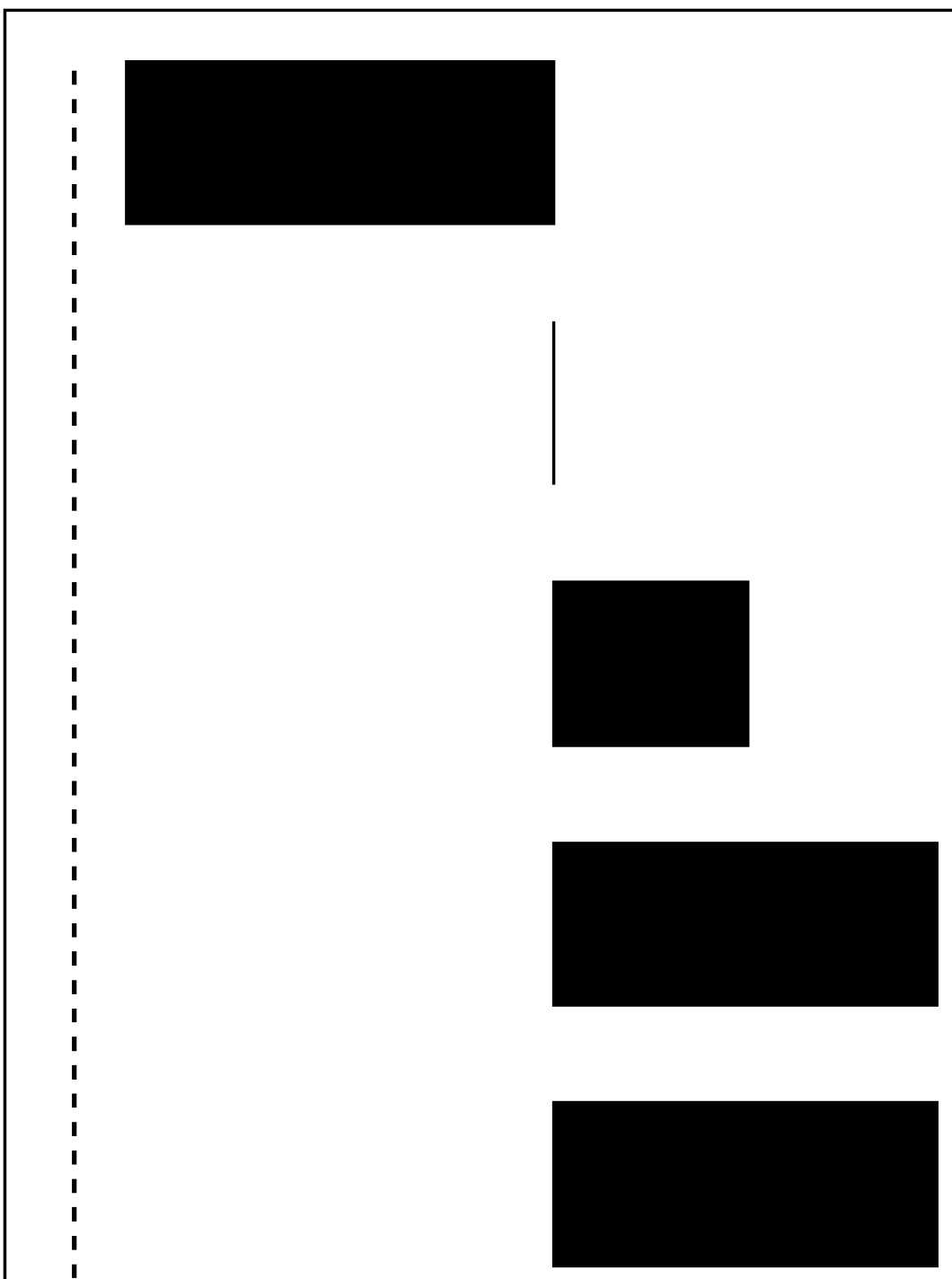
Basement membrane-specific heparan sulfate proteoglycan core protein precursor

Platelet glycoprotein Ib alpha chain precursor

Von Willebrand factor precursor

Thrombospondin 1 precursor

Collagen alpha 1 (III) chain precursor

Splice Isoform A of Collagen alpha 6(IV) chain precursor

Laminin, alpha 2

Splice Isoform Alpha-3A of Integrin alpha-3 precursor

Splice Isoform XB of Tenascin-X precursor

Vitronectin precursor

Splice Isoform 1 of Tenascin precursor

Splice Isoform B of Collagen alpha $1(\mathrm{XI})$ chain precursor

AlphA 1 type II collAgen isoform 2, preproprotein

Splice Isoform 10 of Fibronectin precursor

Splice Isoform 1 of Fibronectin precursor

Fibronectin 1 isoForm 4 preproprotein

Hypothetical protein DKFZp686K08164

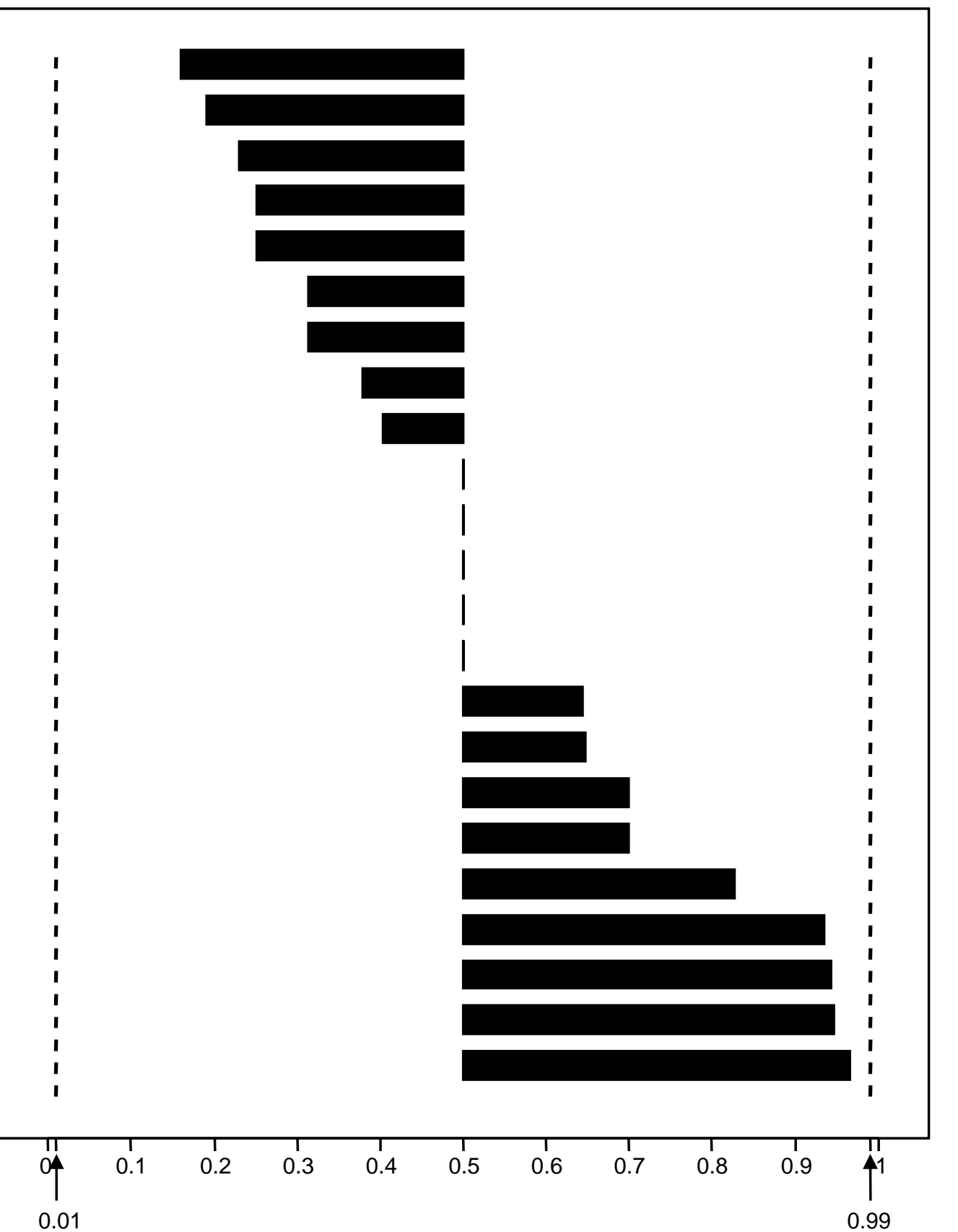

$p$ value 
TGF-beta signaling pathway

Tumor necrosis factor precursor

Thrombospondin-4 precursor

Thrombospondin-2 precursor

Thrombospondin 1 precursor

Mothers against decapentaplegic homolog 7

CREB-binding protein

Cartilage oligomeric matrix protein precursor

Bone morphogenetic protein 6 precursor

Mothers against decapentaplegic homolog 5

DeDicator of cytokinesis 5
Enriched in diabetic serum Enriched in non-diabetic serum
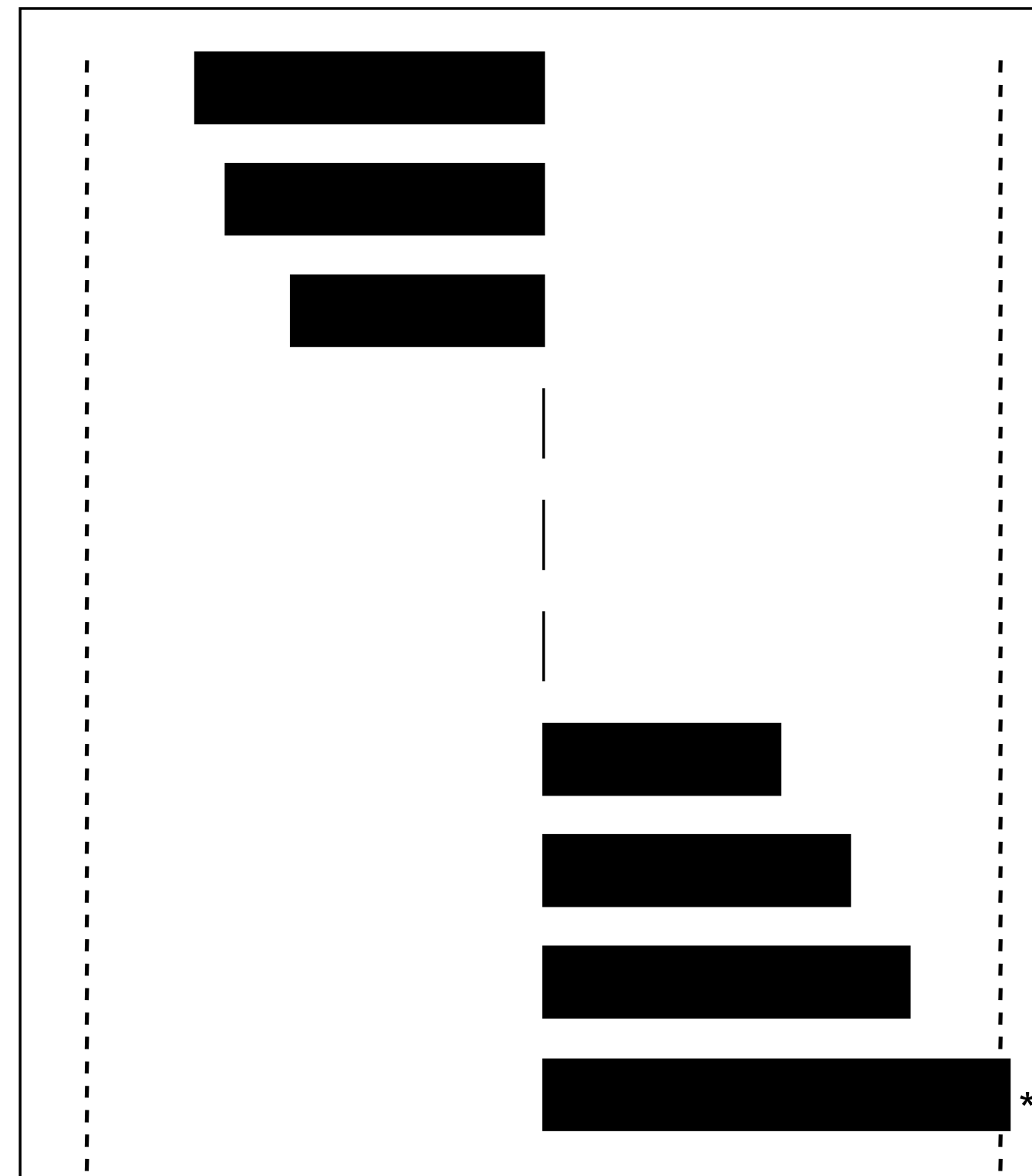

I

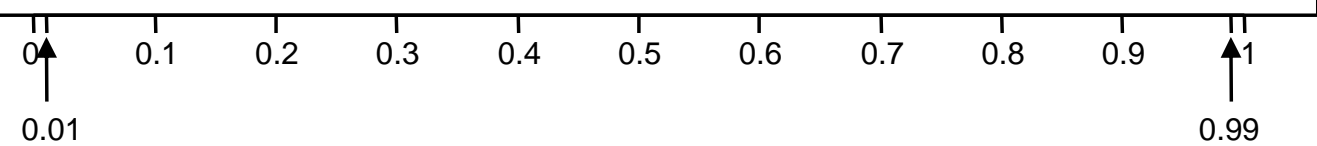

$p$ value 
Coagulation cascade

Alpha-2-macroglobulin precursor

Splice Isoform 1 of Coagulation factor XI precursor

Antithrombin III variant

Plasma serine protease inhibitor precursor

Vitamin K-dependent protein S precursor

Heparin cofactor II precursor

Coagulation factor $X$ precursor

Von Willebrand factor precursor

Coagulation factor XIII A chain precursor

Vitamin K-dependent protein C precursor

Splice Isoform HMW of Kininogen precursor

Splice Isoform LMW of Kininogen precursor

Plasminogen precursor

Coagulation factor XIII B chain precursor

Alpha-1-antitrypsin precursor

Splice Isoform Alpha-E of Fibrinogen alpha/alpha-E chain precursor

Coagulation factor XII precursor

Coagulation factor $\mathrm{V}$

Coagulation factor IX precursor

Alpha-2-antiplasmin precursor

Splice Isoform Gamma-B of Fibrinogen gamma chain precursor

SERPINC1 protein

Plasma protease $\mathbf{C} 1$ inhibitor precursor

Prothrombin precursor

Factor VII active site mutant immunoconjugate

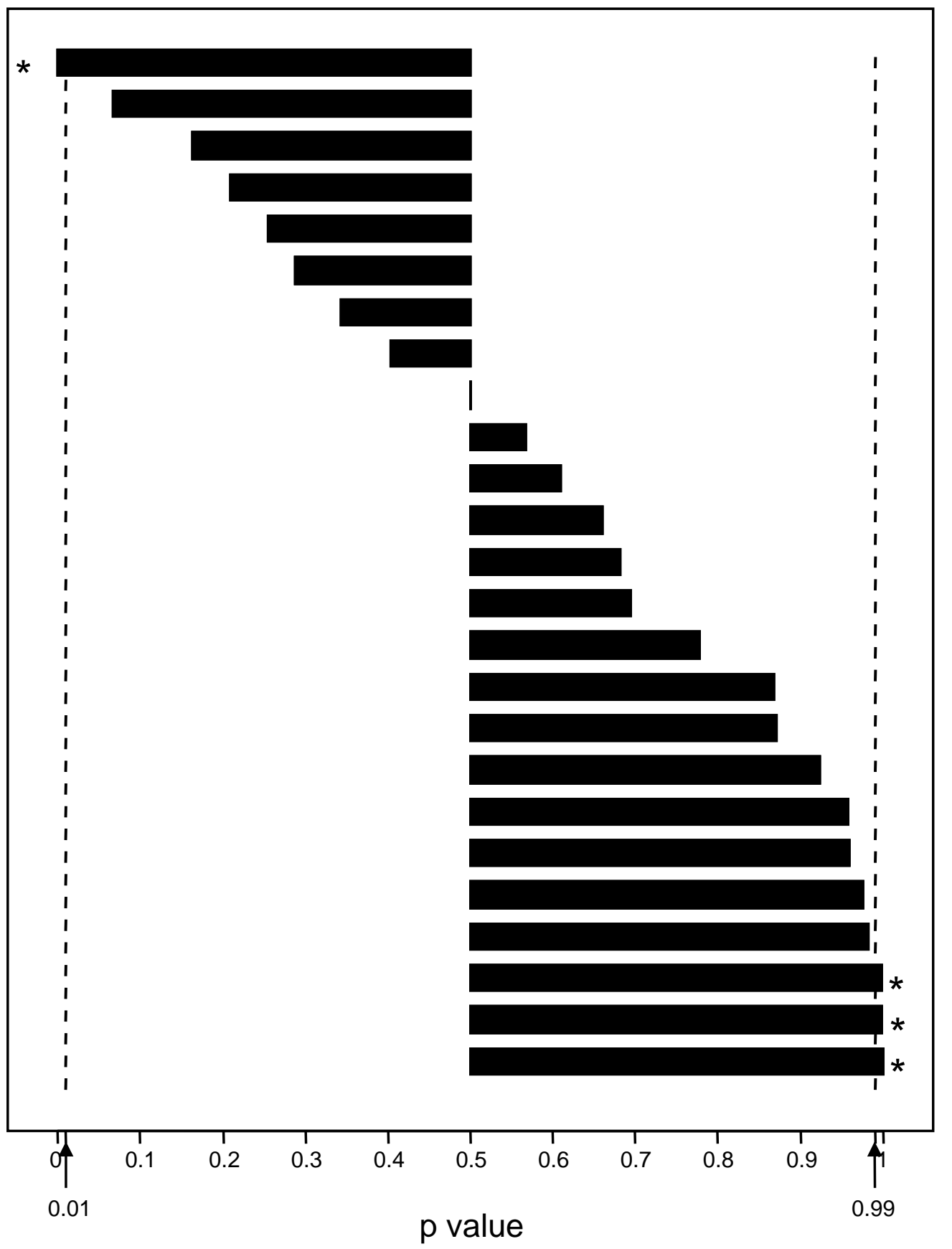




\section{Small cell lung cancer}

Retinoic acid receptor RXR-gamma

Hypothetical protein PIK3CG

Splice Isoform A of Collagen alpha 6(IV) chain precursor

Laminin, alpha 2

Nitric-oxide synthase, endothelial

Splice Isoform Alpha-3A of Integrin alpha-3 precursor

Splice Isoform 1 of Apoptotic protease activating factor 1

Splice Isoform 1 of Nitric-oxide synthase, brain

Splice Isoform 10 of Fibronectin precursor

Splice Isoform 1 of Fibronectin precursor

Fibronectin 1 isoForm 4 preproprotein

Hypothetical protein DKFZp686K08164

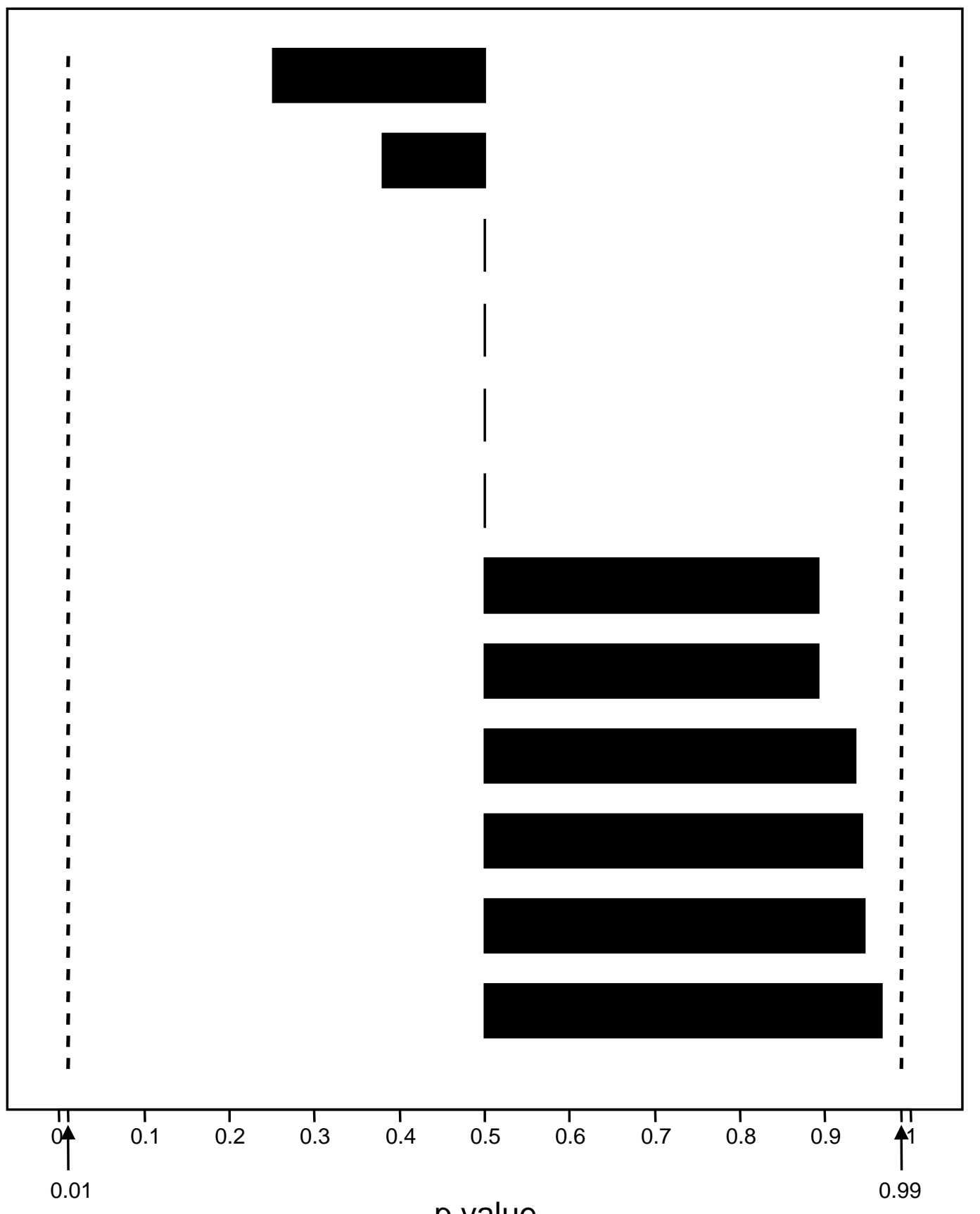




\section{Insulin signaling pathway}

cAMP-dependent protein kinase type II-beta regulatory subunit

Hypothetical protein PIK3CG

Similar to 6-phosphofructokinase, liver type

SH2 containing inositol-5-phosphatase

Fructose-1,6-bisphosphatase

Sorbin and SH3 domain containing 1

Forkhead box protein $\mathrm{O} 1 \mathrm{~A}$

Splice Isoform 1 of Tripartite motif protein 9

Splice Isoform 1 of Phosphorylase b kinase alpha regulatory chain, skeletal muscle isoform

Splice Isoform Alpha-1 of Mitogen-activated protein kinase 10

Glycogen phosphorylase, muscle form

Glycogen phosphorylase, brain form

Insulin receptor substrate 2 insertion mutant
Enriched in diabetic serum

Enriched in non-diabetic serum
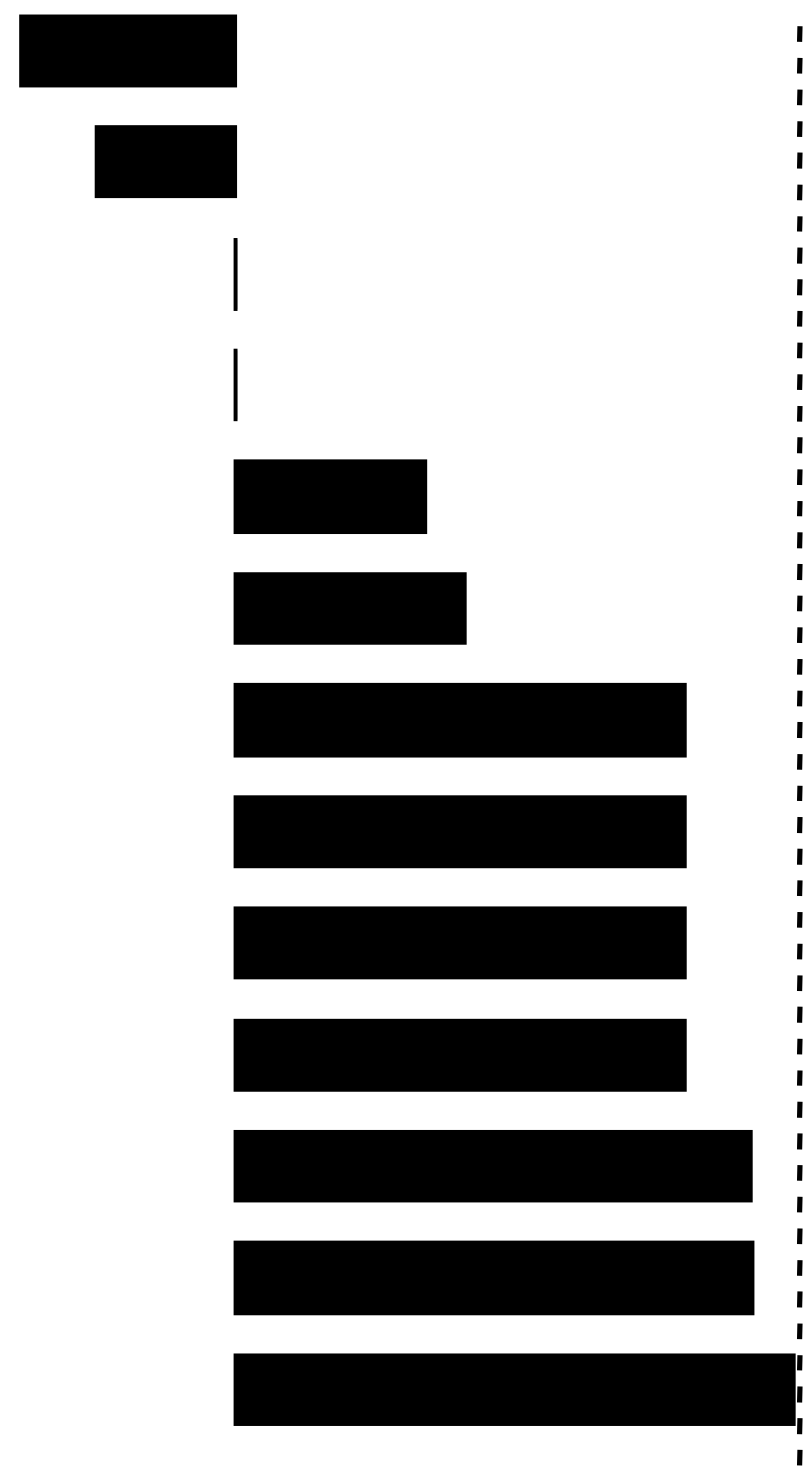

0.1

0.2

0.3

0.4

0.5

0.6

$p$ value 
Focal adhesion

Thrombospondin-4 precursor

Thrombospondin-2 precursor collagen, type III, alpha 1 protein

Splice Isoform Long of Integrin beta-7 precursor Collagen alpha 3(V) chain precursor

FLJ00343 protein

Hypothetical protein PIK3CG Von Willebrand factor precursor

Thrombospondin 1 precursor Collagen alpha 1(III) chain precursor Splice Isoform A of Collagen alpha 6(IV) chain precursor Laminin, alpha 2 Titin

Splice Isoform Alpha-3A of Integrin alpha-3 precursor

Splice Isoform XB of Tenascin-X precursor

Vitronectin precursor Alpha-actinin 1

Rho-GTPase-activating protein 5 Splice Isoform 1 of Tenascin precursor Splice Isoform B of Collagen alpha 1(XI) chain precursor

Cartilage oligomeric matrix protein precursor

Splice Isoform 1 of Filamin C

AlphA 1 type II collAgen isoform 2, preproprotein

Talin 2

Splice Isoform Alpha- 1 of Mitogen-activated protein kinase 10

Insulin-like growth factor I receptor precursor

Splice Isoform 10 of Fibronectin precursor

Splice Isoform 1 of Fibronectin precursor

Fibronectin 1 isoForm 4 preproprotein

Titin

TiTin isoform novex-1

Titin, heart isoform N2-B

Hypothetical protein DKFZp686K08164

Actin, cytoplasmic 1

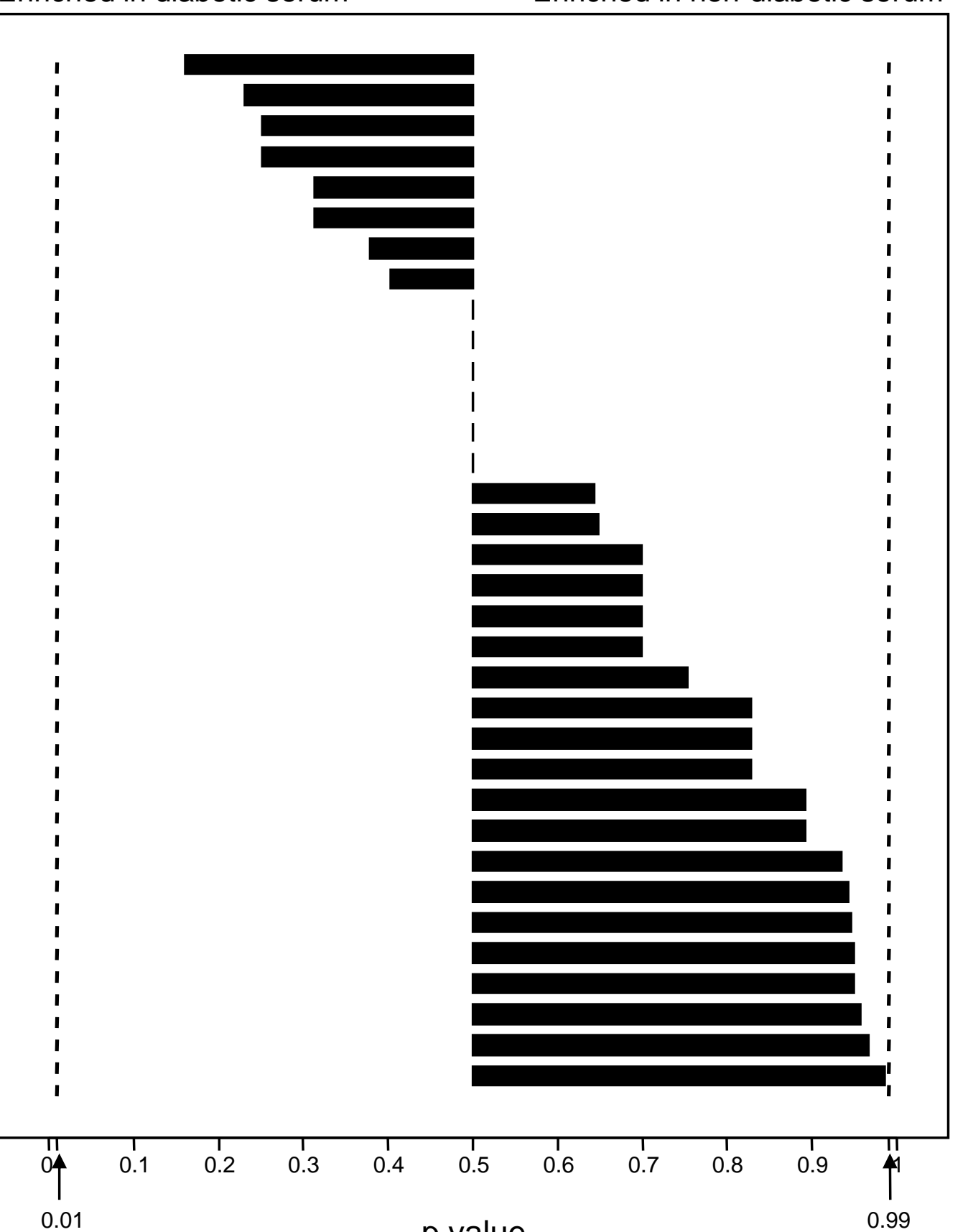


Long term depression

Splice Isoform Flop of Glutamate receptor 1 precursor

Nitric-oxide synthase, endothelial

Cytosolic phospholipase A2

Splice Isoform 3 of Ryanodine receptor 1

Splice Isoform 1 of Ryanodine receptor 1

Splice Isoform 1 of Nitric-oxide synthase, brain

Insulin-like growth factor I receptor precursor

1-phosphatidylinositol-4,5-bisphosphate phosphodiesterase beta 2

DeDicator of cytokinesis 5
Enriched in diabetic serum

Enriched in non-diabetic serum

i
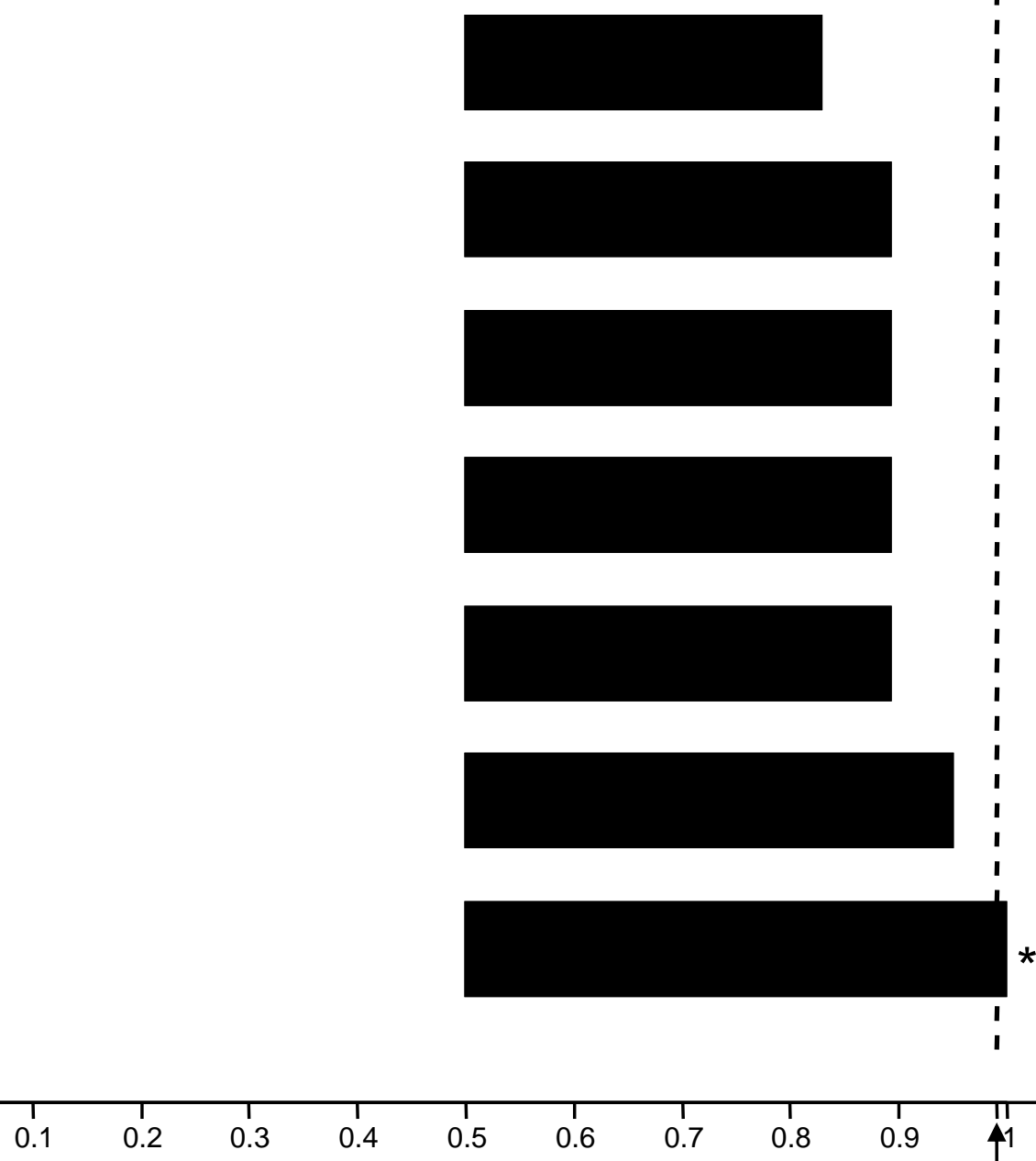